American J. of Engineering and Applied Sciences 2 (4): 708-712, 2009

ISSN 1941-7020

(C) 2009 Science Publications

\title{
Mathematical Modeling of the Three Phase Induction Motor Couple to DC Motor in Hybrid Electric Vehicle
}

\author{
${ }^{1,2}$ Zulkarnain Lubis, ${ }^{2}$ A.N. Abdalla, ${ }^{2}$ Mortaza and ${ }^{1,2}$ Ruzlaini Ghon \\ ${ }^{1}$ Faculty of Electrical and Automation Engineering Technology, \\ TATi University College, Malaysia \\ ${ }^{2}$ Faculty of Electrical and Electronic Engineering, University Malaysia Pahang, \\ Kuantan, Malaysia
}

\begin{abstract}
Problem statement: With emphasis on a cleaner environment and efficient operation, vehicles today rely more and more heavily on electrical power generation for success. Approach: Mathematical modeling the components of the HEV as the three phase induction motor couple to DC motor in hybrid electric vehicle was introduced. The controller of Induction Motor (IM) was designed based on inputoutput feedback linearization technique. It allowed greater electrical generation capacity and the fuel economy and emissions benefits of hybrid electric automotive propulsion. Results: A typical series hybrid electric vehicle was modeled and investigated. Conclusion: Various tests, such as acceleration traversing ramp and fuel consumption and emission were performed on the proposed model of 3 phase induction motor coupler DC motor in electric hybrid vehicles drive.
\end{abstract}

Key words: Hybrid electrical vehicle, induction motor, DC machine

\section{INTRODUCTION}

With the oil price shocks of the past few decades, as well as an increasing awareness of the emissions of air pollutants and greenhouse gases from cars and trucks, the interest to investigate alternative vehicle propulsion systems has grown. This challenge of fuel economy standards is promoting optimized and sometimes novel vehicle power-train architectures, which combine the traditional Internal Combustion Engine (ICE) with various forms of electric drives. The different types of the Hybrid Electric Vehicles (HEV) are real competitors of the classical ICE driven cars.

In an all-Electric Vehicle (EV) there is no ICE, but all other components exist including batteries with excessive power. EVs and HEVs are studied by numerous authors in the past, one comprehensive study is that of Chan ${ }^{[1]}$. First full-scale hybrid vehicle work in Turkey is Doblo/Tofas example realized at Marmara Research Centre ${ }^{[2]}$. There have been university theses and an industry project constitutes the basics of this study ${ }^{[3-7]}$. One of the main contribution is that of Gokce $^{[4]}$, energy conservation and energy balance method is adopted. The input-output feedback linearization technique combined with an adaptive backstopping observer in stator reference frame the induction motor ${ }^{[5]}$ using in series hybrid electric vehicle is controlled ${ }^{[8]}$.
This study focus on a new HEV modeling to make a couple two electric motor IM and DCM close loop sinusoidal PWM inverter to control the speed of a three phase induction motor. This compact inverter had its hardware reduced to a minimum through the use of a Programmable Integrated Circuit (PIC) micro-controller (PIC16C73A). In this sense a microcomputer interface was avoided. At the end, a typical HEV is modeled and investigated. Simulation results obtained show the IM and other components performances for a typical city drive cycle.

\section{MATERIALS AND METHODS}

The performance of an electric vehicle: The first step in vehicle performance modeling is to write an equation for the electric force. This is the force transmitted to the ground through the drive wheels and propelling the vehicle forward. This force must overcome the road load and accelerate the vehicle as shown in Fig. 1.

The rolling resistance is primarily due to the friction of the vehicle tires on the road and can be written as:

$\mathrm{f}_{\text {roll }}=\mathrm{f}_{\mathrm{r}} \mathrm{Mg}$

Where:

$\mathrm{M}=$ The vehicle mass

$\mathrm{f}=$ The rolling resistance coefficient and $\mathrm{g}$ is gravity acceleration

Corresponding Author: Zulkarnain Lubis, Faculty of Electrical and Automation Engineering Technology,

TATi University College, Malaysia 


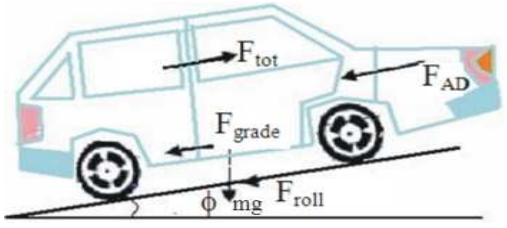

Fig. 1: Basic of forces on a vehicle

The aerodynamic drag is due to the friction of the body of vehicle moving through the air. The formula for this component is as in the following. Dynamic modeling and simulation of an induction motor with:

$\mathrm{f}_{\mathrm{AD}}=\frac{1}{2} \xi \mathrm{C}_{\mathrm{D}} A \mathrm{~V}^{2}$

The gravity force due to the slope of the road can be expressed by:

$f_{\text {grade }}=M g \cdot \sin \alpha$

where, $\alpha$ is the grade angle.

In addition to the forces shown in Fig. 3, another one is needed to provide the linear acceleration of the vehicle given by:

$\mathrm{f}_{\mathrm{acc}}=\mathrm{M} \alpha=\mathrm{M} \frac{\mathrm{dv}}{\mathrm{dt}}$

The propulsion system must now overcome the road loads and accelerate the vehicle by the tractive force, $\mathrm{F}_{\mathrm{tot}}$, as follows:

$\mathrm{F}_{\text {tot }}=\mathrm{f}_{\text {roll }}+\mathrm{f}_{\mathrm{AD}}+\mathrm{f}_{\text {garde }}+\mathrm{f}_{\text {acc }}$

A typical road load characteristic as a function of the speed and mass of a vehicle is shown in Fig. 2. Wheels and axels convert $F_{\text {tot }}$ and the speed of vehicle to torque and angular speed requirements for differential as follows:

$\mathrm{T}_{\text {whell }}=\mathrm{F}_{\text {tot }} \mathrm{r}_{\text {wheel }}, \omega_{\text {wheel }}=\mathrm{V} / \mathrm{r}_{\text {wheel }}$

where, $T_{\text {whell }}, r_{\text {wheel }}$ and $\omega_{\text {wheel }}$ are the tractive torque, the radius and the angular velocity at the wheels, respectively.

The angular torque velocity and torque of the wheels are converted to motor rpm and motor torque requirements using the gears ratio at differential and gearbox as follows:

$\omega_{\mathrm{m}}=\mathrm{G}_{\mathrm{fd}} \mathrm{G}_{\mathrm{gb}} \omega_{\text {wheel }}, \mathrm{T}_{\mathrm{m}}=\mathrm{T}_{\text {whell }} / \mathrm{G}_{\mathrm{fd}} \mathrm{G}_{\mathrm{gb}}$

where, $\mathrm{G}_{\mathrm{fd}}$ and $\mathrm{G}_{\mathrm{gb}}$ are respectively differential and gear box gears ratios.

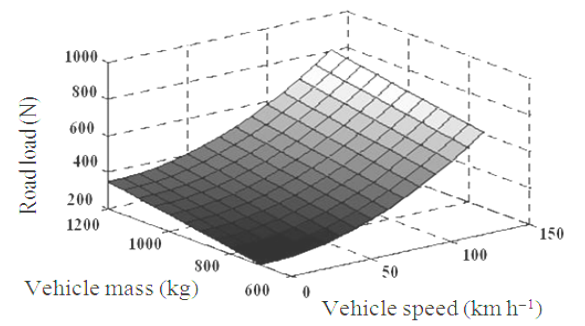

Fig. 2: Summary of forces on a vehicle

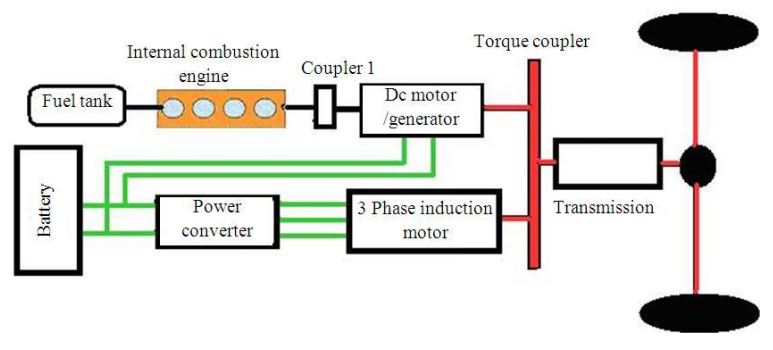

Fig. 3: Power assembly diagram of HEV

Proposed method: A Hybrid Electrical Vehicle (HEV) may consist of an Internal Combustion Engine (ICE), Electric Motor (EM), Electric Generator (EG), power electronic circuits, advanced Electronic Control Units (ECU), a complex mechanical transmission and a battery bank.

Figure 3 shows the structure of drive assembly of a hybrid electric car (There are electrical machines, generator and starter $(\mathrm{M} / \mathrm{G})$, starter and the main Motor (M)). G/M is an Integrated Started and Generator (ISG) which connects with the Internal Combustion Engine (ICE) using a couple. The starter is a standby one. The $\mathrm{M}$, which is subject of this study, is called main motor. It connects with the wheels through the final gear. Main motor is a three phase asynchronous Motor. The battery pack is a $288 \mathrm{~V}, 10 \mathrm{Ah} \mathrm{NiH}$ one (Fig. 3).

The hybrid electric car has 8 working modes: Idle stop, ICE drive motor drive, serial mode, parallel mode, serial and parallel mode, ICE drive, battery charge and regenerative braking. Figure 2 shows four of the modes. ICE stops running when it is in the idle running state and may be restarted in less than $100 \mathrm{~ms}$ by the M/G. The idle stop mode will reduce fuel consumption and emissions in idle running state. The ICE drive mode is the same as the traditional car and will occur in most efficient working area of ICE. The motor drive mode is the same as the battery electric car and will occur at very low speed. In Variasi mode which is shown in Fig. 4, the ICE drags the M/G to charge the battery and the main induction motor. 


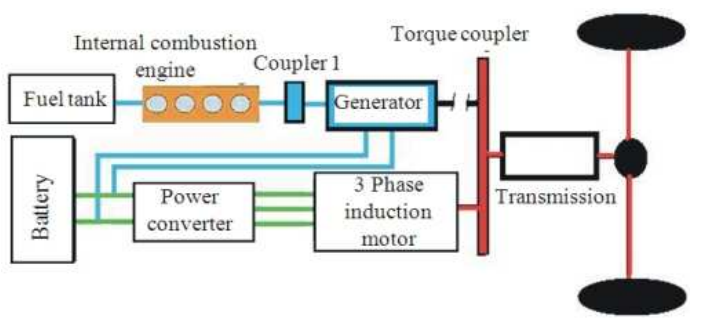

(a)

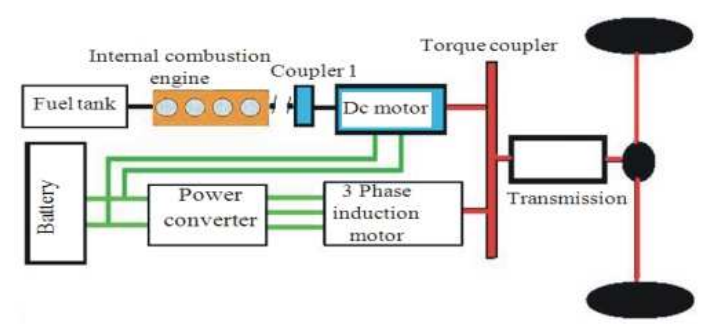

(b)

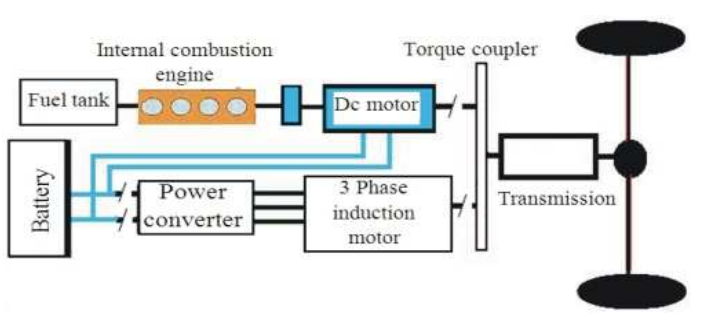

(c)

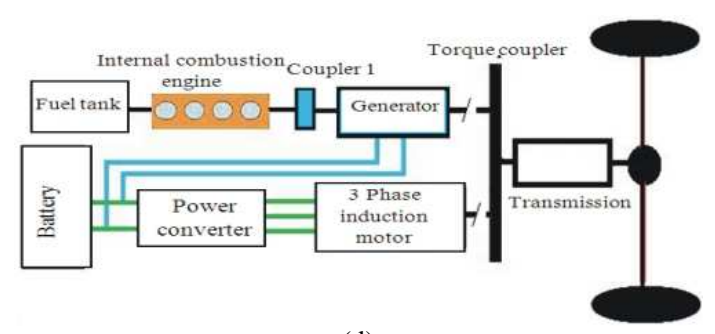

(d)

Fig. 4: Operation of 3 phase induction motor coupler DC motor in electric hybrid vehicles drive. (a): Car run normal condition; (b): Car run in hybrid electric; (c): Car standby (OFF); (d): Starting 3 phase induction motor

\section{RESULTS}

First the system is simulated for DCM+IM test cycle. Due to the electric motor has been modeled dynamically in SIMULINK. The data for IM and EV is in the appendix. Figure 5 shows the simulation block diagram. The drive cycle gives the required vehicle speed then the torque and speed requested from the electric motor. The current drawn from IM power supply shows the battery performance.

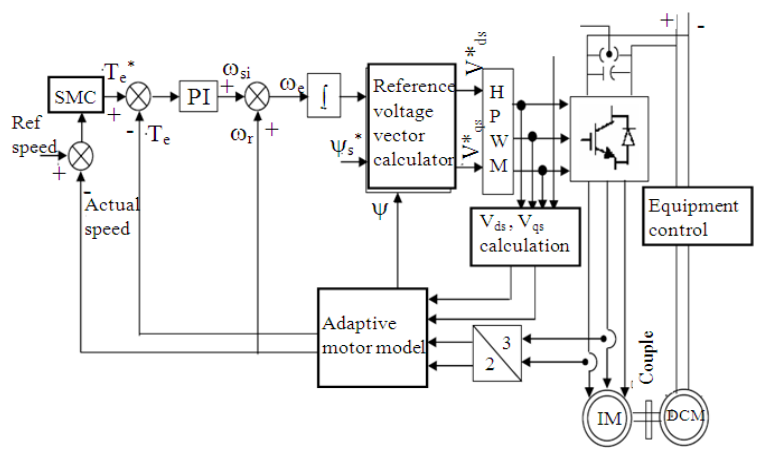

Fig. 5: Block diagram of hybrid electric induction motor

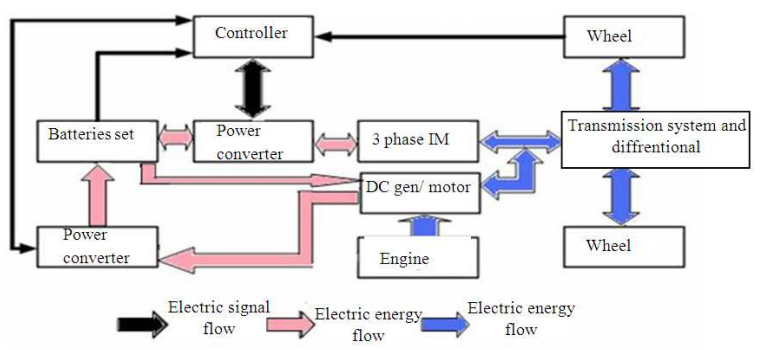

Fig. 6: Simulation block diagram

The dynamic behavior of the IM in the DCM+IM drive cycle is shown in Fig. 4a and b. Figure 4a shows Power assembly diagram of HEV Normal Condition the ECE drive cycle. Figure $4 \mathrm{c}$ and $\mathrm{d}$ show the IM torque and average torque, power assembly diagram of $\mathrm{HEV}$ in Hybrid Electric.

Results is explained by the pact that, in experimental test were observed a strong influence of motor inductance in coupler to DC motor, more precisely, in the power system, however in the simulation such influence was not considered and also non-linearity and additional losses. Figure7 shows optimal torque in hybrid electric vehicle with Thee phase Induction motor coupled with DC motor $\mathrm{T}_{\mathrm{IM}+\mathrm{DCM}}$. Figure 8 shows results comparison-couple the Three phase Induction Motor and DC Motor.

\section{DISCUSSION}

Figure 4 and Table 1 working mode and power flow route of HEV drives the wheel. In parallel mode which is shown in Fig. 4b, both the ICE and the main motor drive the wheels. Parallel mode occurs when high output is needed. The serial and parallel mode is shown in Fig. 4c. When the state of charge of the battery is low, the ICE drags the M/G to charge the battery and drives the wheels at the same time. 
Am. J. Engg. \& Applied Sci., 2 (4): 708-712, 2009

Table 1: Operation of three phase induction motor coupler DC motor in electric hybrid vehicles drive

\begin{tabular}{|c|c|c|c|c|}
\hline Equipment & Operation 1 & Operation 2 & Operation 3 & Operation 4 \\
\hline & $\begin{array}{l}\text { Car run use energy } \\
\text { three phase induction motor } \\
\text { Supply from battery }\end{array}$ & $\begin{array}{l}\text { Car run use energy } \\
\text { three phase induction } \\
\text { motor and adaptive } \\
\text { energy DC motor }\end{array}$ & $\begin{array}{l}\text { Car starting engine use } \\
\text { energy battery to on DC } \\
\text { Motor }\end{array}$ & $\begin{array}{l}\text { Starting three induction } \\
\text { motor use energy } \\
\text { battery and generator } \\
\text { DC }\end{array}$ \\
\hline Engine & Run & Run & start & Run \\
\hline DC machine & $\begin{array}{l}\text { As generator to charger } \\
\text { battery }\end{array}$ & $\begin{array}{l}\text { Run as motor and coupler } \\
\text { with } 3 \text { phase induction motor }\end{array}$ & $\begin{array}{l}\text { As motor starter to run } \\
\text { engine }\end{array}$ & $\begin{array}{l}\text { As generator to charger } \\
\text { battery }\end{array}$ \\
\hline $\begin{array}{l}\text { Three phase } \\
\text { Induction motor }\end{array}$ & Run & Run & Stop & Start \\
\hline Coupler 1 & Close & Close & Close & Close \\
\hline Torque coupler 2 & Open & Close & Open & Close \\
\hline Battery & Charger & Discharger & Discharger & Charger \\
\hline
\end{tabular}

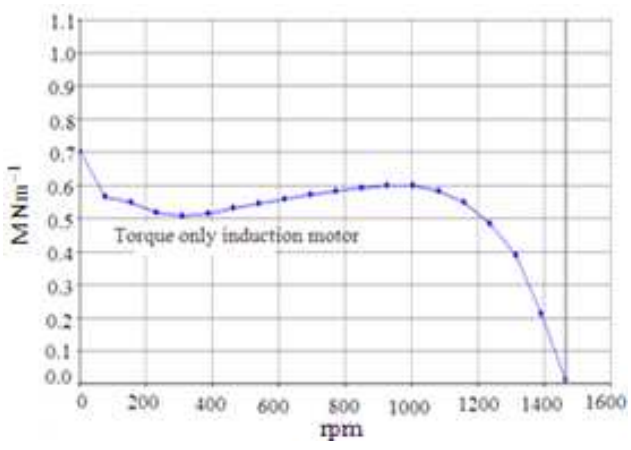

(a)

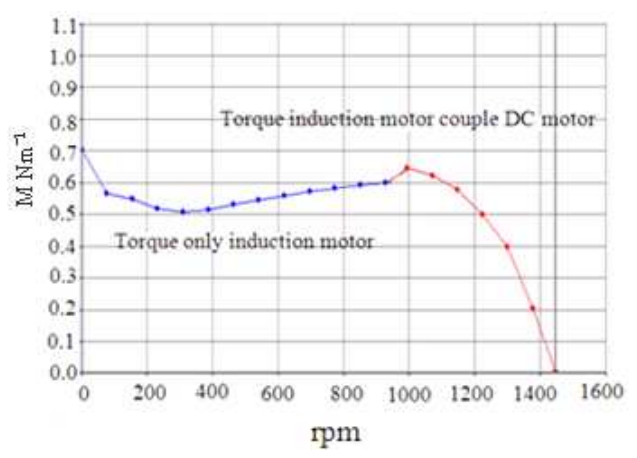

(b)

Fig. 7: Experimental torque of (a): Thee phase induction motor; (b): Thee phase induction motor coupled with DC motor $\mathrm{T}_{\mathrm{IM}+\mathrm{DCM}}$

In the regenerative brake mode shown in Fig. 4d, the $\mathrm{M} / \mathrm{G}$ and the main motor work in generator mode to charge the battery. These will decrease the fuel consumption.

The three-phase induction motor speed control was couple to DC motor in close loop schematic, as shown Fig. 5 and 8 Torque data was acquired through a Hall Effect sensor, with a torque relation speed for each $0.1 \mathrm{Nm}$ shown in scale we have $1500 \mathrm{rpm}$ as resulting speed.

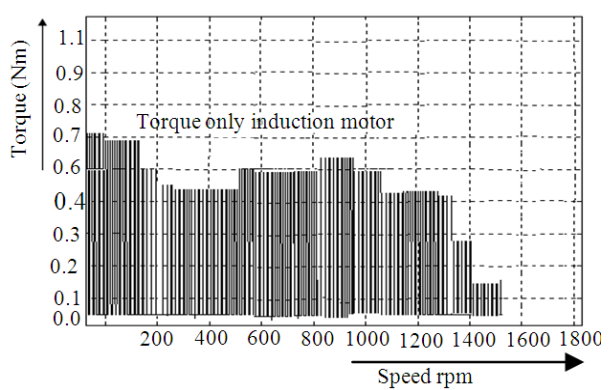

(a)

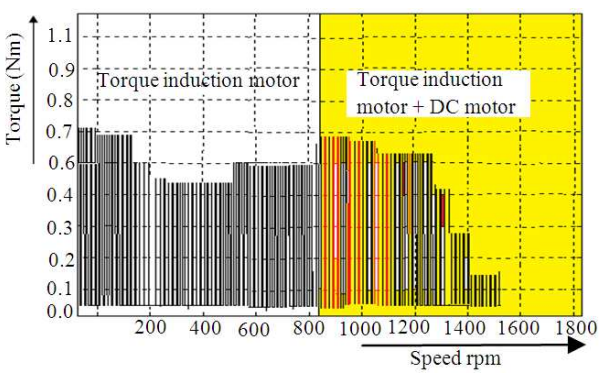

(b)

Fig. 8: Simulation result's (a): Three phase induction motor $\mathrm{T}_{\max } \mathrm{IM}=0.7 \mathrm{M} \mathrm{Nm}^{-1}$ (b): Couple three phase induction motor and $\mathrm{DC}$ motor $\mathrm{T}_{\mathrm{IM}+\mathrm{DCM}}$

\section{CONCLUSION}

Hybrid vehicles are coming on the transportation scene as a means to meet the increasing challenges of fuel economy and low emission of greenhouse gases. Technical and business considerations based on market demands are driving hybrid vehicle architectures to be improved day by day. In this study, the couple of the two electric motors with input-output state feedback controller combined with adaptive back-stepping observer and batteries of a typical series hybrid EV is investigated and simulated by Matlab/Simulink, has been presented and the performance and ability of control strategy is investigated. Steady-state simulation 
tools have been developed for the design and analysis of electric and hybrid electric vehicles. Simulation results have also been shown the IM and IM+DCM, maximum torque in graph Fig. 7 and 8.

\section{ACKNOWLEDGEMENT}

The researchers thank the Faculty of Electrical and Electronic Engineering, of WHO that funded the project with resources received for research from university Malaysia Pahang.

\section{REFERENCES}

1. Chan, C.C., 2002. The state of art of electric and hybrid vehicles. Proc. IEEE, 90: 247-275. http://cat.inist.fr/?aModele $=$ afficheN\&cpsidt $=1355$ 4416

2. Chen, K., A. Bouscayrol, A. Berthon, P. Delarue, D. Hissel and R. Trigui, 2008. Global modeling of different vehicles using energetic macroscopic representation. Proceedings of the Vehicle Power and Propulsion Conference, Sept. 3-5, IEEE Xplore Press, Harbin, pp: 1-7. DOI: 10.1109/VPPC.2008.4677728

3. Gao, D.W., C. Mi and A. Emadi, 2006. Modeling and simulation of electric and hybrid vehicles. Proc. IEEE, 95: 729-745. DOI: 10.1109/JPROC.2006.890127
4. Yimin G., S.E. Gay, M. Ehsani, R.F. Thelen and R.E. Hebner, 2003. Flywheel electric motor/generator characterization for hybrid vehicles. Proceedings of the IEEE 58th Vehicular Technology Conference, VTC 2003-Fall, Oct. 6-9, IEEE Xplore Press, USA., pp: 3321-3325. DOI: 10.1109/VETECF.1286291

5. Singh, B. and J. Ravi, 2006. Modified direct torque control of matrix converter fed induction motor drive power electronics, drives and energy systems. Proceedings of the International Conference on Pedes, Dec. 12-15, IEEE Xplore Press, USA., pp: 1-7. DOI: 10.1109/PEDES.2006.344383

6. Yuan Z. and Xu Longya, 2006. Application of dual mechanical port machine in hybrid electrical vehicles. Proceedings of the Vehicle Power and Propulsion Conference, Sept. 6-8, IEEE Xplore Press, Windsor, pp: 1-5. DOI: 10.1109/VPPC.2006.364304

7. Kuo, K.S., L.J. Shang, H.Z. Chen and K.W. Jwo, 2004. Flux compensated direct torque control of induction motor drives for low speed operation power electronics. IEEE Trans., 19: 1608-1613. DOI: 10.1109/TPEL.2004.836618

8. Barsali, S., M. Ceraolo and A. Possenti, 2002. Techniques to control the electricity generation in a series hybrid electrical vehicle. Energy Conversion IEEE Trans., 17: 260-266. DOI: 10.1109/TEC.2002.1009478 